\title{
AÇAÍ BLOG: UM BLOG PEDAGÓGICO PARA USO NA ESCOLA E NA FORMAÇÃO DE PROFESSORES
}

\begin{abstract}
Resumo. Os uso de blogs pedagógicos ou educativos é ainda uma novidade que exige adaptações de diferentes naturezas, quer para programadores, quer para usuários, os alunos e professores dos diferentes níveis de ensino. Por essa razão, em 2003, o Laboratório de Estudos em Educação a Distância (Le@d.CAp) iniciou o desenvolvimento de um blog, o Açaí, com o intuito de implementar um dispositivo útil às finalidades pedagógicas do Colégio de Aplicação/UFRGS (CAp), bem como às de investigação sistemática das transformações e impactos que derivam de seu uso. Desde a sua primeira versão o Açaí ofereceu um espaço para escrita compartilhada de textos (posts) aos quais é possível anexar arquivos (imagens, sons, textos, vídeo etc.) bem como receber comentários. O processo de desenvolvimento do Açaí Blog implicou a análise do seu uso em no acompanhamento de projetos de aprendizagem de crianças (Ensino Fundamental), bem como em cursos a distância para formação continuada de educadores. Os fundamentos psicológicos e epistemológicos da teoria de Jean Piaget foram utilizados como fundamentação para a construção de determinadas funcionalidades desse sistema no que diz respeito à organização das interações dos usuários do sistema. Palavras-chave: educação a distância, blog, educação básica e formação de professores.
\end{abstract}

\section{Apresentação}

O uso de blogs pessoais, hoje em dia, vem se difundindo em proporções inestimáveis, sendo um dos meios preferidos para a comunicação interpessoal entre o público jovem. Não é possível estabelecer corretamente o número de blogs publicados no mundo. Acredita-se que um blog é criado a cada segundo. Levantamentos jornalísticos mostram que, entre os blogs existentes, a grande maioria pertence a usuários entre 15 a 25 anos. A criação e utilização de blogs tem sido difundida entre crianças, jovens e adultos por permitirem a publicação de páginas na web sem a necessidade de um conhecimento prévio de linguagem html. A atualização do blog se faz via posts que são textos elaborados pelo autor ou por diferentes visitantes, o que agrega às possibilidades de autoria um elevado grau de liberdade. É facilmente constatável que os blogs têm sido utilizados para diferentes finalidades, desde as estritamente pessoais até as profissionais relacionadas a corporações e instituições de todos os gêneros: empresas, política, escolas etc.

No que diz respeito aos objetivos de investigação do Laboratório de Estudos em Educação a Distância da UFRGS - Le@d.CAp, voltados ao desenvolvimento e à implementação de atividades de educação a distância, ao aperfeiçoamento pedagógico mediante a utilização das tecnologias de informação e comunicação na educação básica, a testagem e/ou construção de sistemas para a web que permitam interação e compartilhamento de produções é fundamental. Levando-se em consideração os processos educacionais em modificação acelerada, que exigem estudos sobre impactos e transformações pedagógicas relacionadas ao uso crescente de ambientes informatizados 
de aprendizagem e desenvolvimento de experiências em rede, este grupo de pesquisa está desenvolvendo desde 2003 uma ferramenta de produção e compartilhamento de textos para internet denominada, em sua versão atual, de Açaí Blog.

O Açaí Blog é uma ferramenta que visa o registro e o acompanhamento de atividades cotidianas dentro de uma ou diversas comunidades. Apresenta-se como um ambiente de criação e edição de comunidades e blogs pessoais (diários de bordo virtuais) inter-relacionados que possibilitam o acompanhamento dos processos que envolvem a aprendizagem tanto de crianças e jovens quanto de educadores em formação. Caracteriza-se por atender uma demanda pedagógica de comunicação e registro de atividades de professores, alunos e demais usuários da internet que não estejam cadastrados nesse sistema, promovendo a possibilidade de amplas interações entre esses.

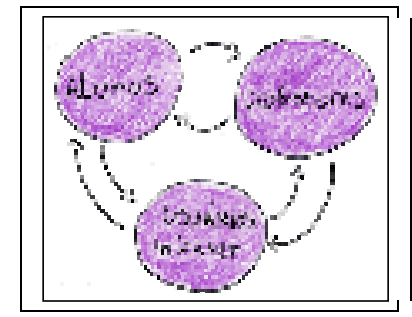

Figura 1. Possibilidades de interação no Açaí Blog

Desde o início do desenvolvimento o Açaí Blog foi desenhado para utilizar uma base de dados SQL que armazena todos os dados relacionados aos usuários do sistema, os textos característicos dos posts de um blog, bem como todos os outros dados que caracterizam a interface para a web: descrição de comunidades, biblioteca de imagens e links, arquivos que podem ser anexados às postagens (som, vídeo, texto etc), os registros de inclusão e/ou exclusão dos usuários nas diferentes comunidades e os comentários de internautas cadastrados ou não no sistema. A programação da interface é desenvolvida essencialmente na linguagem PHP sendo utilizado, para alguns casos em que é preciso fazer seleção de diferentes dados, o JavaScript.

Além de relatar brevemente o desenvolvimento do sistema que permite o funcionamento do Açaí Blog e descrever suas funcionalidades, intenção desse trabalho é relacionar as demandas que implicaram o seu desenvolvimento a partir de uma sustentação construtivista, baseada em Piaget (1990), como forma de suscitar reflexões a respeito do uso das tecnologias de informação e comunicação na Educação Básica.

\section{A cronologia do desenvolvimento do sistema}

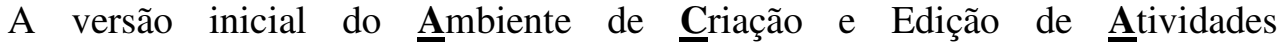
Interdisciplinares - de onde se tirou o apelido Açaí - teve seu desenvolvimento iniciado no final de 2003 para atender a uma demanda de registro compartilhado de atividades interdisciplinares desenvolvidas no âmbito do Projeto Amora (Colégio de Aplicação/UFRGS). O Amora é um projeto de reestruturação curricular desenvolvido no Ensino Fundamental no qual se pretende, dentre outros objetivos, constituir um grupo de professores orientados para um trabalho eminentemente interdisciplinar. 


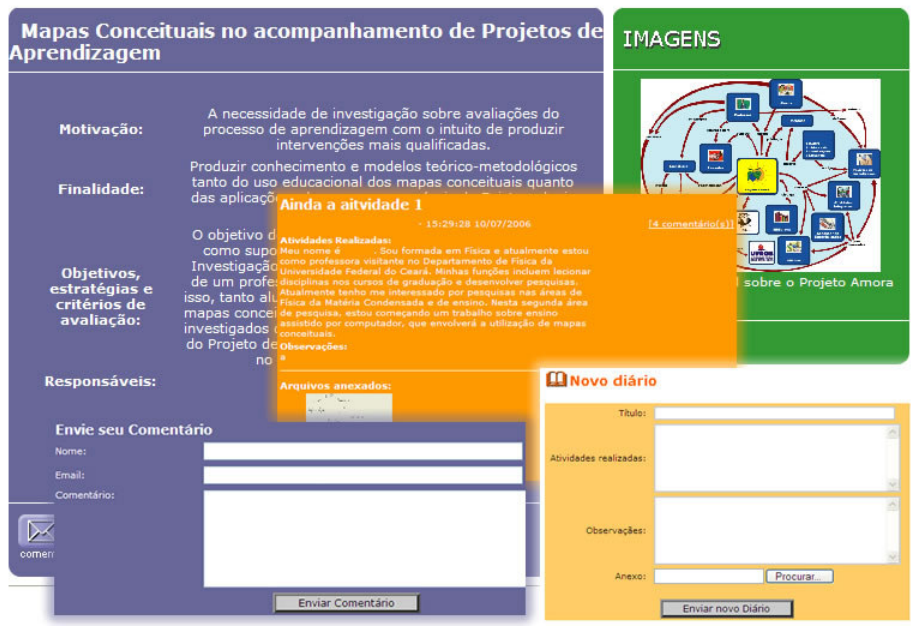

Figura 2. Primeira versão do ambiente Açaí

Dessa forma, o sistema cuja interface gráfica pode ser vista na Figura 3, permitia que diferentes usuários fossem responsáveis pela edição e registro de uma atividade. Já era possível deixar registrados no sistema a motivação, a finalidade, os objetivos, as estratégias e os critérios de avaliação das atividades. Além disso, estava disponível uma interface para se construir uma biblioteca de imagens e outra para o salvamento de links associados à cada atividade. Uma vez criada a atividade no sistema, os responsáveis poderiam editar e salvar diários de bordo que ficavam organizados em ordem cronológica decrescente e aos quais se podia anexar arquivos de texto e de imagem que podiam ser acessados através dos links ao final do diário.

Essa primeira versão já permitia a interação de usuários cadastrados no sistema ou outros internautas através da envio de comentários associados tanto à descrição da atividade quanto a um diário em específico.

Durante o ano de 2004 os testes do sistema foram realizados pelo grupo de professores do Projeto Amora bem como no desenvolvimento de um portal educacional voltado ao uso de mapas conceituais na educação (http://mapasconceituais.cap.ufrgs.br).

O tipo de atividade característica do Colégio de Aplicação da UFRGS (onde se desenvolve o Projeto Amora e onde está sediado o Laboratório de Estudos em Educação a Distância) envolve o trabalho com crianças e jovens alunos da educação básica. Por essa razão, o desenvolvimento natural do sistema nos levou a duas novas demandas: a criação de uma interface mais adequada para o uso de crianças e a constituição de diferentes comunidades virtuais cujos registros precisavam ser adaptáveis às necessidades de cada uma (como os projetos de aprendizagem, por exemplo, que surgem de iniciativas das crianças).

O desenvolvimento de uma nova interface do Açaí, precisava considerar a programação das funcionalidades previamente estabelecidas bem como os requisitos que estavam sendo planejados para o desenvolvimento das novas. Uma concepção visual foi desenvolvida preservando praticamente toda a estrutura de códigos que sustentam o layout. Inicialmente foram desenvolvidos protótipos gráficos que privilegiavam a organização dos espaços e dos conteúdos dinâmicos cuja intenção era 
de que pudessem ser gerenciados e customizados pelos usuários. Durante o processo de adequação da interface foram adotadas as seguintes estratégias:

- análise da interface antiga afim de identificar as principais deficiências conforme a estrutura;

- desenvolvimento de uma nova interface orientada a facilitar a utilização da ferramenta, tendo em vista o público alvo; e

- implementação e testes junto a equipe de programação

A ênfase desse projeto, do ponto de vista do design gráfico adotado, foi a elaboração de uma interface que respeitasse certos critérios: a aplicação de uma dinâmica cromática; a adequação dos elementos quanto a estrutura; a escolha relevante de imagens que correspondessem ao tema, mesclando-se ao layout de forma coerente; e a constituição de uma tipografia e iconografia.

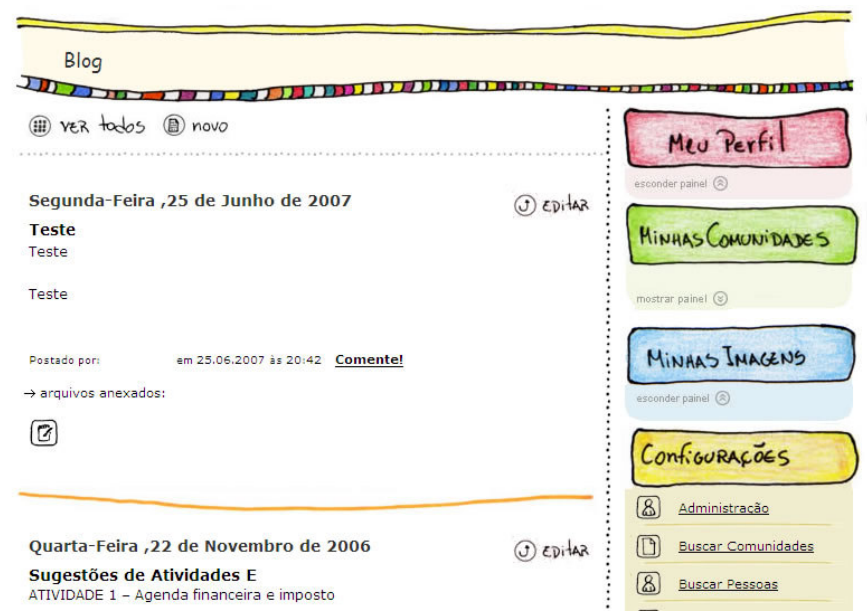

Figura 3. Uma das interfaces atuais do Açaí Blog

Com isso, em uma segunda fase do desenvolvimento do sistema já se tem implementados dois layouts gráficos (um deles pode ser observado na Figura 3) que o usuário escolhe tanto no momento em que se cadastra no sistema com a possibilidade de alterá-lo a qualquer momento.

Entretanto, as modificações de maior impacto no sistema estão relacionadas ao modo de como os usuários produzem os textos que são armazenados no banco de dados. Conservando-se a essência do primeiro ambiente desenvolvido, o Açaí Blog passou a adotar o usuário como principal elemento de organização das informações recebidas. 


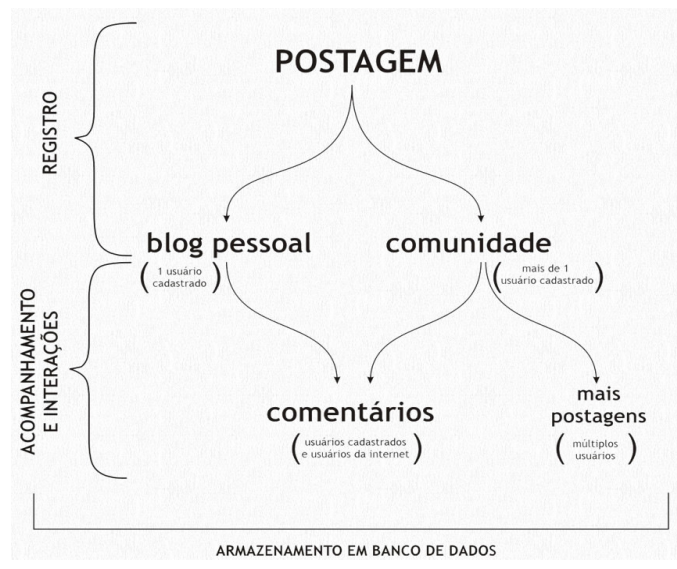

Figura 4. Esquema da organização das postagens na versão atual do Açaí Blog

A Figura 4 ilustra a forma com que uma postagem de usuário pode ser organizada. Ao ingressar no sistema um indivíduo é imediatamente direcionado para uma área denominada blog pessoal no qual são exibidas todas as postagens de sua autoria organizadas cronologicamente. Contudo, fica permitido ao usuário criar diferentes tipos de comunidades nas quais ele adiciona outros usuários. No momento de construir e enviar um novo post, o usuário pode, então, escolher se deseja que aquele texto seja exibido em uma determinada comunidade a qual pertence ou se ele deve estar apenas no seu blog pessoal. Dessa forma, ao se acessar uma comunidade lá estão exibidos os textos dos diferentes usuários que compõem aquela referida comunidade em ordem cronológica decrescente mas, o usuário pode, em seu blog pessoal acompanhar apenas os textos de sua autoria.

As funcionalidades existentes na versão anterior (biblioteca de imagens e links, descrição da atividade, possibilidade de anexar arquivos aos posts e o envio de comentários) foram todas incorporadas pela Comunidade do Açaí Blog. Além disso o sistema passou a reconhecer os diferentes tipos de anexos aos posts e a exibir um ícone correspondente: textos, imagens, sons, vídeos etc. Também se tornou possível prévisualizar as imagens anexadas usando-se thumbnails. 


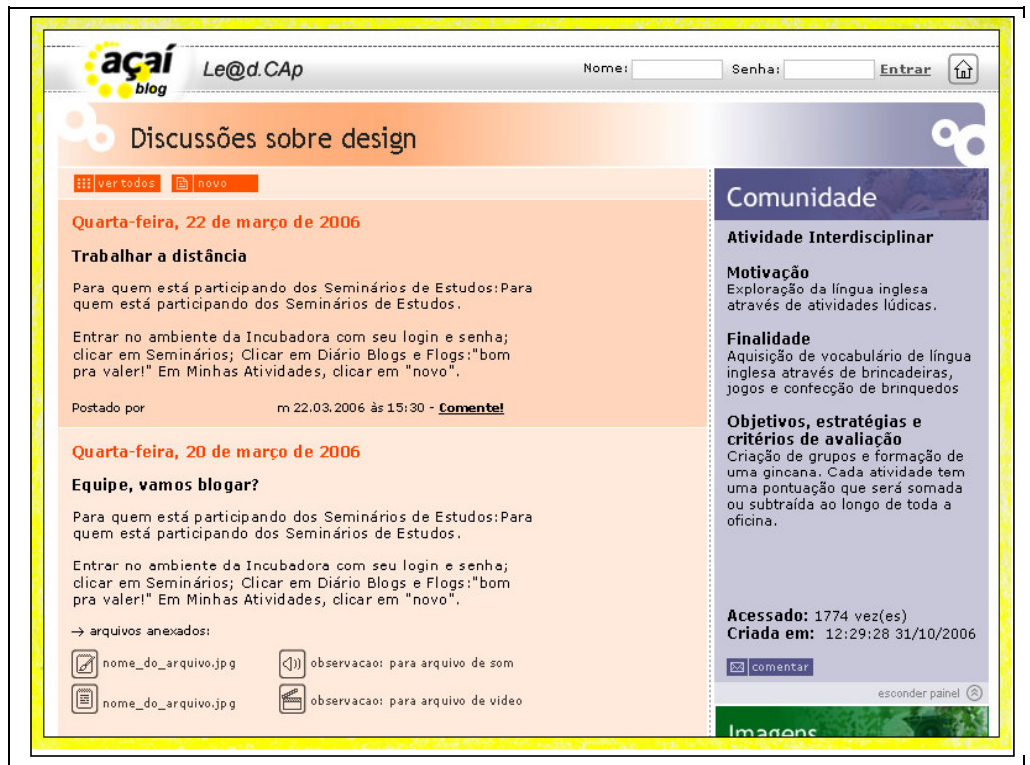

Figura 5. Tela de uma comunidade do Açaí Blog

Para poder abrigar diferentes tipos de comunidades o sistema precisava de uma diferenciação que o tornasse capaz de armazenar no banco de dados quais os campos descritores necessários para cada uma delas. Assim, foi implementada uma funcionalidade para um usuário administrador que lhe permite criar diferentes tipos de comunidade descrevendo, desde o nome de cada tipo até os descritores de cada campo.

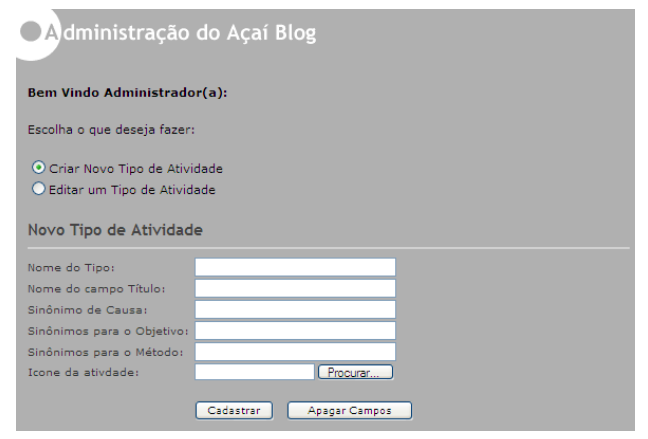

Figura 6. Interface para criação de diferentes comunidades

A Figura 6 mostra a interface que permite a criação de cada comunidade. Como já mencionado anteriormente, um tipo de organização de atividade que é rotina no Projeto Amora são os projetos de aprendizagem. Para tanto, o Açaí Blog recebe como campos descritores: Pergunta Inicial (ao invés de Título da Atividade), Por que queremos fazer essas investigações? (em lugar dos objetivos da atividade), Hipótese Inicial, palavras chave (em vez de finalidade) e Outras perguntas do projeto (no lugar de Estratégias etc).

A usabilidade do Açaí Blog vem sendo testada, desde 2006, em outras atividades que incluem desde a orientação a bolsistas de iniciação científica do Le@d.CAp, a 
realização de cursos de extensão a distância e até o desenvolvimento de disciplina de Pós-Graduação (mestrado).

O principal interesse de investigação e desenvolvimento desse sistema está ligado ao fato das possibilidades de autoria e interação que ele permite. Apresentaremos, na seção seguinte alguns exemplos das possibilidades de tal ferramenta.

\section{As possibilidades de autoria. A promoção e o registro de interações}

Piaget coloca em evidência a atividade do sujeito como condição necessária à aquisição de novos conhecimentos. Para ele, o conhecimento "resultaria de interações que se produzem a meio caminho entre o sujeito e o objeto, e que dependem, portanto, dos dois ao mesmo tempo, mas em virtude de uma indiferenciação completa e não de trocas entre formas distintas" (Piaget, 1990). No contexto do que estamos tratando nesse trabalho, quais seriam as possíveis interações sujeito-objeto em um blog?

Tomemos o exemplo a seguir que trata de um texto de uma criança de 10 anos com interesse sobre desenho animado:

Sexta-Feira , 14 de Setembro de 2007

DESENHO

Eu vi um video que fala sobre como faz o desenho que o desenho é feito pelo computador mas no video estava mostrando a mão como se faz o desenho. Atualizado por: GES em 14.09.2007 às 09:31 [5] Comentários

O objeto de conhecimento aqui, para esse sujeito, é o desenho feito no computador. O registro produzido por ela trata de uma certa estranheza sua devido ao fato de um desenho feito pelo computador precisa de um desenho feito à mão ou, ainda, que seria necessário desenhar à mão no computador. De fato, o que tal registro deixa ver é que, em um determinado momento as significações da aluna sobre "desenho feito no computador" ao interagirem com uma informação que não se encaixavam exatamente nas suas concepções provocando então, uma necessidade de "agir" para poder acomodar esse "comportamento estranho" do objeto. De fato a produção dessa criança uma vez publicada em um ambiente que permite o compartilhamento através da internet pôde receber intervenções (Comentários) tais como: (CAR, 10 anos) E é preciso algum material especial? 08:04:36 28/09/2007, (Docente) Olha que eu achei. <link para um site com informações sobre a história do desenho animado > 08:25:37 28/09/2007 .

A cargo do processo de desenvolvimento cognitivo está a função de adaptação, constituída na regulação e auto-organização das trocas do indivíduo com o meio. Essa função engloba dois processos indissociáveis e que tendem a um equilíbrio, em geral nunca atingido a não ser a título de etapas provisórias (Piaget, 1976). A assimilação é a incorporação de um elemento exterior a um esquema de ação ou a um conceitual do sujeito. Acomodação é a necessidade em que se acha a assimilação de levar em conta as particularidades próprias dos elementos a assimilar.

Em decorrência das implicações da atividade do indivíduo nas interações com o meio, os esquemas de assimilação coordenam-se em sistemas, progressivamente estruturando o que Piaget chama de sistema de significações do sujeito. No modelo piagetiano, é a equilibração cognitiva o mecanismo que explica as regulações, desencadeadas por perturbações (assimilação das novidades), que são responsáveis, seja 
na ação ou posteriormente usando representações, pelo desenvolvimento das estruturas (lógicas) que asseguram as condições para as aprendizagens do sujeito.

Em uma análise preliminar (estudo exploratório) dos dados e registros disponíveis no Açaí Blog já é possível observar as potencialidades de uso das ferramentas de interação do mesmo. As análises produzidas estão voltadas principalmente para a caracterização das interações (qualidade e indicativos do tipo de interação) que os registros e ações no blog permitem observar.

Pode-se acompanhar a organização dos textos através da cronologia das postagens nas comunidades, podendo, assim, analisar como se desenrolou o processo da construção de um conhecimento (conceito, noção etc).

Tomemos como exemplo a postagem de uma criança durante a realização de um projeto de aprendizagem sobre o funcionamento do corpo humano.

Orgãos.
Na biblioteca eu encontrei informações como:
1-Cada uma das partes, de um organismo que se incube de realizar certa função
espacifica. 2-O coração e os vasos sanguíneos e o sangue forma o sistema
cardiovascular. 3-O cérebro, os nervos e os tecidos ligados a eles formam o sistema
nervoso. 4-A boca o estomago e os intestinos trabalham juntos como membros do
sistema digestório. 5-Os músculos respiratórios as veias respiratória (NARIZ,
BOCA, FARINGE, LARINGE E TRAQUEIA) e os pulmões trabalham juntos
fomando o sistema respiratório. 6- Do que é feito o corpo humano? -células vivas. -o
laberinto intracélulas.
*TODOS OS SISTEMAS JUNTOS FORMAM O SEU ORGANISMO.
Postado por: DIE em 14.11.2006 às 07:16 [4]comentário(s)

O conjunto de comentários no quadro a seguir, enviados por colegas do mesmo grupo da aluna, demonstram que é possível que os próprios alunos realizem intervenções no sentido de diferenciar conceitos e apresentar as "resistências" dos objetos de conhecimento que estão compartilhando.

Comentário 1 : BRU
Acharia melhor se você revisasse o seu texto por que há alguns erros de ortografia,
achei muito legal a estrutura do teu texto.
08:46:22 14/11/2006
Comentário 1 : VIC
DIE eu achei bem interesante a tua pesquisa, mas tem palavras que eu não conheço,
tipo labirinto intracélulas e essas coisas, mas mesmo assim eu ache muito
interessante o tue projeto
08:41:47 14/11/2006
Comentário 1: VOL
Eu acho que você poderia explicar o que é um LABIRINTO intracélulas.
$08: 15: 11$ 14/11/2006

08:15:11 14/11/2006 
Comentário 1 : JEA
O que é o organismo e quantas partes são?
08:12:50 14/11/2006

As próprias crianças interviram no sentido de esclarecer os isgnificado de plavras (conceitos) empregados e, até mesmo, na correção ortográfica de algumas palavras: Eu acho que você poderia explicar o que é um LABIRINTO intracélulas.

\section{Considerações finais e perspectivas}

O Açaí Blog, além do diferencial de permitir a organização de usuários e suas respectivas produções em diferentes tipos de comunidades, possui uma peculiaridade fundamental para a produção de análises sobre o uso de blogs na educação: o armazenamento em bancos de dados. Essa peculiaridade permite o acesso e a organização das produções registradas nesse sistema de forma a contribuir com investigações sobre o seu uso e as possibilidades de autoria e e os tipos de interação possibilitadas.

Além disso, a flexibilidade de configuração das diferentes comunidades virtuais permitida pelo Açaí Blog

Contudo, para que essas análises possam ser eficazes, precisamos estabelecer uma metodologia de uso do Açaí Blog em atividades educionais, afim de produzir experimentos controlados através das trocas em comentários e a associação de textos nas comunidades. Tais estudos já foram iniciados e resultados preliminares têm sido divulgados (Dutra, 2006b; 2006c).

Espera-se que mais análises em profundidade sejam realizadas e que possam contribuir para a produção de intervenções mais eficazes nos processos de aprendizagem tanto de crianças e jovens quanto de professores em formação.

\section{Referências}

Dutra, Í. M. (2006a). Mapas Conceituais no acompanhamento dos processos de conceituação. Tese de Doutorado. Centro Interdisciplinar de Novas Tecnologias na Educação. Programa de Pós-graduação em Informática na Educação. Porto Alegre.

Dutra, Í. M. ; Piccinini, C. A.; Becker, J. L. ; Johann, S. P. ; Fagundes, L. C. (2006b) Blog, wiki e mapas conceituais digitais no desenvolvimento de Projetos de Aprendizagem com alunos do Ensino Fundamental. RENOTE. Revista Novas Tecnologias na Educação, v. 4, p. 1-8.

Dutra, Í. M. ; Piccinini, C. A.; Becker, J. L. ; Johann, S. P. ; Fagundes, L. C. (2006c). Uma base de dados para compartilhamento de experiências no uso de mapas conceituais no acompanhamento de processos de conceituação. RENOTE. Revista Novas Tecnologias na Educação, v. 4, p. 1-10, 2006.

Grize, J. B. (1996). Logique naturelle et communication. Paris: PUF.

Grize, J. B. (1997). Psicologia Genética e Lógica. In Banks-Leite, L. (Org.). Percursos Piagetianos. São Paulo: Cortez. 
Inhelder, B. \& Piaget, J. (1976). Da lógica da criança à lógica do adolescente. São Paulo: Pioneira.

Piaget, J. (1976a). Ensaio de Lógica Operatória. Porto Alegre: Globo.

Piaget, J. (1976b). A equilibração das estruturas Cognitivas: Problema Central do Desenvolvimento. São Paulo: Zahar.

Piaget, J. (1977). A tomada de consciência. São Paulo: Melhoramentos.

Piaget, J. (1978). Fazer e compreender. São Paulo: Melhoramentos.

Piaget, J. \& Garcia, R. (1989). Hacia una logica de significaciones. Cidade do México: Gedisa.

Piaget, J. (1990). Epistemologia Genética. São Paulo: Martins Fontes.

Piaget, J. (1995). Abstração Reflexionante. Porto Alegre: Artes Médicas. 